\title{
Five-Year Efficacy of Transobturator Tape Treatment and Quality of Life in Women with Stress Urinary Incontinence
}

\author{
Mehmet Oguz Sahin, $\mathrm{MD}^{1 *}$; Volkan Sen, $\mathbf{M D}^{1}$; Bora Irer, $\mathrm{MD}^{2}$; Guner Yildiz, $\mathrm{MD}^{3}$ \\ ${ }^{1}$ Department of Urology, Manisa State Hospital, Manisa, Turkey \\ 2Department of Urology, Izmir Metropolitan Municipality Esrefpasa Hospital, Izmir, Turkey \\ ${ }^{3}$ Department of Urology, Dr. Suat Seren Chest Diseases and Surgery Training and Research Hospital, Izmir, Turkey
}

\begin{abstract}
Background: We aimed to assess the results of first- and fifth-year outcomes and the effect on quality of life (QoL) of transobturator tape (TOT) treatment in patients with stress urinary incontinence (SUI).

Methods: The patients who underwent TOT surgery between January 2008 and June 2013 were screened retrospectively. The QoL was evaluated with Incontinence Impact Questionnaire (IIQ-7) and Urogenital Distress Inventory-Short Form (UDI-6). The subjective evaluation of patients in terms of incontinence outcome was classified as worsened (UDI-6 and IIQ-7 if pre-operative $<$ postoperative), improved (UDI-6 and IIQ-7 if pre-operative > postoperative), or cured (UDI-6 and IIQ-7 postoperative $<10$ ). The first-year and fifth-year success rates were compared between the IIQ-7 and UDI-6 results.

Results: A total of 109 patients were included in the study. There was a significant improvement $(P<0.001)$ in the patients' UDI-6 and IIQ-7 scores when the preoperative and postoperative first-year results were compared. Comparing the postoperative firstyear and fifth-year total UDI-6 and IIQ-7 scores, a significant improvement was observed and the patients' complaints were significantly reduced $(P<0.001)$. The results of the IIQ-7 and UDI-6 questionnaire revealed that the TOT surgery success rate was $93.3 \%$ at the end of the first year and $88.7 \%$ at the end of the fifth year.

Conclusion: The postoperative first-year and fifth-year data reveal that TOT surgery has a high success rate and positive effects on QoL. Low complication rates and the ease of application make TOT a good alternative to other treatment modalities in surgical treatment of SUI.

Keywords: Complications, Incontinence, Quality of life, Stress urinary incontinence, Transobturator tape

Cite this article as: Sahin MO, Sen V, Irer B, Yildiz G. Five-year efficacy of transobturator tape treatment and quality of life in women with stress urinary incontinence. Arch Iran Med. 2020;23(12):827-834. doi: 10.34172/aim.2020.110.
\end{abstract}

Received: September 28, 2019, Accepted: June 20, 2020, ePublished: December 1, 2020

\section{Introduction}

Urinary incontinence is described by the International Continence Society (ICS) as involuntary urine loss, and the most common types include urgency urinary incontinence (UUI), stress urinary incontinence (SUI), and mixed urinary incontinence. ${ }^{1}$ Urinary incontinence is a condition that negatively affects quality of life (QoL) for physical, social and hygienic reasons. ${ }^{2}$ SUI occurs when bladder pressure exceeds urethral resistance due to an increase in abdominal pressure during exercise, sneezing or coughing, and its prevalence is reported to vary between $4 \%-35 \%$ in previous studies. ${ }^{3,4}$ In SUI treatment, in addition to conservative methods, such as pelvic muscle exercises, surgical methods such as tension-free vaginal tape (TVT) and the Burch colposuspension, can be used. ${ }^{5}$ Transobturator tape (TOT) treatment, first described in 2001, is another alternative mid-urethral sling technique, in which an artificial mesh is placed through the obturator foramen. ${ }^{6}$ Although the TOT success rates are reported to be similar to TVT, TOT has come to the forefront due to its shorter operation time and lower complication rate, and it has become the most commonly used method in the treatment of SUI today. ${ }^{7}$

There are only a limited number of studies in the literature on the long-term outcomes of TOT treatment. In the present study, we aimed to evaluate the results of first-and fifth-year outcomes and the effect on QoL of TOT treatment applied to female patients with SUI.
Patients and Methods
Patients
Following the approval of the local ethics committee, we retrospectively screened the data from patients who underwent suburethral tension-free vaginal TOT surgery due to SUI in our urology clinic (secondary care hospital) between January 2008 and June 2013. Patients who were under 18 years of age, had recurrent urinary tract infections and had incontinence surgery before were excluded from 
the study. Patients who had pure SUI were included in the study. The patients' demographic characteristics, the results of the International Consultation on Incontinence Short-Form Questionnaire (ICIQ-SF), UDI-6 and IIQ-7, QoL, stress test (Marshall-Marchetti cough test, MMK) and Q-tip test, surgical results and complications were recorded. The patients' QoL was evaluated with ICIQ-SF QoL, UDI-6 and IIQ-7 questionnaires. Total IIQ-7 scores ranged between 0-21 and UDI-6 scores ranged between $0-18$ points and the scores were given as percentages ( $21=100 \%$ for IIQ-7 and $18=100 \%$ for UDI-6); higher percentages are associated with worse QoL. All patients underwent complete urinalysis and urine culture in the preoperative period. For the patients who presented with a urinary infection, the operation was undertaken once the urine was sterilized with appropriate antibiotic treatment. The patients who had been previously operated for UI or pelvic organ prolapse, those with an explicit neurological disease or cystocele or rectocele to the extent that required surgical repair and those who used medications increasing the bleeding tendency were excluded from the study. The decision to operate was taken for the cases with a Q-tip test result of $>30$ degrees and positive stress test results. Informed consent was obtained from each patient. Antibiotic prophylaxis was achieved with $2 \mathrm{~g}$ of cefazolin 30 minutes before the operation. All operations were performed by one of the three experienced urology specialists under spinal anesthesia using the outsidein technique. A polypropylene mesh (Unitape $\mathrm{T}$ Promedon $($ ) was used as the TOT material during the operation.

The patients underwent urogynecologic examination. The Q-tip angle, MMK test, operation success, and perioperative complications of patients were assessed and recorded. The validated Turkish versions of the ICIQ-SF, IIQ-7 and UDI-6 questionnaire forms were administered to the patients again at the first-year and fifth-year followup visits. ${ }^{89}$ Patients were evaluated after $1^{\text {st }}$ month, $3^{\text {rd }}$ month, $1^{\text {st }}$ year and then yearly; the $1^{\text {st }}$-year and $5^{\text {th }}$-year results are given in this study. In addition, the subjective evaluation of patients in terms of incontinence outcome was classified as worsened (UDI-6 and IIQ-7 if preoperative < postoperative), improved (UDI-6 and IIQ-7 if pre-operative $>$ postoperative), or cured (UDI-6 and IIQ7 postoperative $<10)$. The first-year and fifth-year success rates were compared between the UDI-6 and IIQ-7 results. Patients did not undergo bladder operations during the follow-up. There were 109 patients operated with TOT at beginning, 90 patients were assessed at $1^{\text {st }}$-year follow-up and 80 patients were assessed at $5^{\text {th }}$-year follow-up.

\section{Statistical Analysis}

The data were analyzed with the Statistical Package for Social Sciences (SPSS, Inc., Chicago IL) version 22 and given as mean \pm standard deviation, number $(n)$ and percentages (\%) with 95\% CI values. The $\chi^{2}$ test was used for comparison of categorical variables, and the Student's t-test, one-way ANOVA and post hoc analysis to compare continuous variables. The Student's paired sample t-test was used to compare between the first-year and fifthyear follow-up scores and preoperative scores. Regression analysis was performed to determine the success of patients at the end of the 1st and 5th years according to the IIQ7 and UDI-6 scores. Analysis results were presented with beta, odds ratio (OR) and $95 \% \mathrm{Cl}$ values. $P$ values $<0.05$ were considered statistically significant.

\section{Results}

A total of 109 patients with a mean age of $52.4 \pm 10.1$ (37-76) years were included in the study. For the first-year and fifth-year follow-up visits, 90 (82.6\%) and 80 (73.4\%) patients could be contacted. The mean body mass index (BMI) of the patients was $26.2 \pm 4.0(20.2-34.4) \mathrm{kg} / \mathrm{m}^{2}$, Q-tip test angles $57.0 \pm 17.1$ (30-90) degrees, follow-up duration $74.4 \pm 46.2(1-138)$ months, operation time $29.7 \pm 9.7(12-60)$ minutes, and hospitalization length $1.2 \pm 0.5$ (1-3) days. For all patients, the cough test (MMK) was positive, UUI was negative, and urodynamic evaluations were normal. In the perioperative period, four women $(3.7 \%)$ had bleeding more than $200 \mathrm{~mL}$, but only one $(0.9 \%)$ required erythrocyte suspension transfusion. Bladder injuries were observed in two (1.8\%) women, for whom the catheter was removed after seven days and an appropriate treatment was administered. Except for two women with bladder injuries, all catheters were withdrawn on the first postoperative day. In the early postoperative period, the catheter was maintained only in two $(1.8 \%)$ patients for seven further days due to acute urinary retention, but these patients had no problems on follow-up. While 22 (20.2\%) women had urgency in the preoperative period, new postoperative urgency was found in three patients $(3.3 \%)$ in the first year and 11 patients $(13.8 \%)$ in the fifth year. In addition, despite the absence of preoperative UUI, $5(5.6 \%)$ and 11 (13.8\%) patients developed UUI in the first-year and fifth-year followup visits, respectively. A significant improvement $(P<$ 0.001) was detected in the patients' IIQ-7, UDI-6, and ICIQ-SF-QoL (Item 5) scores when the preoperative and postoperative first-year results were compared. Comparing the postoperative first-year and fifth-year ICIQ-SF, IIQ7 and UDI-6 total scores, a significant improvement was detected and the patients' complaints were significantly reduced $(P<0.001)$. As an indication of operation efficacy and permanence, the postoperative first-year and fifth-year Q-tip test angles were significantly lower compared to the preoperative values $(P<0.001)$. The MMK cough test was positive in all of the patients preoperatively, while the rate of MMK positivity was $5.6 \%$ in the first postoperative year and $8.7 \%$ in the fifth postoperative year $(P<0.001)$.

According to the results of the UDI-6 and IIQ-7 
questionnaires at the end of the first and fifth years, a significant increase was found $(P<0.001$; except for the first-year IIQ-7 score in the TOT failure group, $P=0.527$ ), compared to the preoperative scores. In the remaining groups (TOT success and clinical improvement), the UDI-6 and IIQ-7 scores were significantly reduced compared to the preoperative values $(P<0.001)$ (Table 1$)$. The comparison of preoperative and $1^{\text {st }}$-year UDI-6, IIQ7, ICIQ-SF and ICIQ-SF QoL scores and the comparison of preoperative and $5^{\text {th }}$-year UDI-6, IIQ-7, ICIQ-SF and ICIQ-SF QoL scores are given in detail in Table 2.

The results of the IIQ-7 and UDI-6 questionnaire revealed that the TOT surgery success rate was $93.3 \%$ at the end of the first year and $88.7 \%$ at the end of the fifth year. When the first and fifth years were evaluated separately using the same questionnaires with univariate analysis (post-hoc analysis), patient age, BMI, preoperative Q-tip angle, operation time, number of hospitalization days, obesity, systemic disease, menopause, and preoperative IIQ-7 score did not affect these success rates. As the preoperative ICIQ-SF, ICIQ-SF item 5 QoL and UDI6 scores increased, the TOT failure rates increased $\left(P_{<}\right.$
0.001, $P=0.004$ and $P=0.002$, respectively for the first year and $P=0.004, P=0.002$ and $P<0.001$ respectively for the fifth year) (Tables 3 and 4 ). In multivariate analysis, success according to IIQ-7 scores was independently associated with lower preoperative UDI-6 scores at $1^{\text {st }}$ and $5^{\text {th }}$ years. However, lower preoperative UDI-6 score was independently associated with only $5^{\text {th }}$-year success of TOT when success was evaluated with UDI-6 scores (Table 5).

Furthermore, in two patients, the TOT success rate was decreased in the first year $(P=0.039)$ due to perioperative complications (bleeding and acute urinary retention), but the same result was not obtained at the fifth year.

\section{Discussion}

Urinary incontinence is a sociocultural health problem with high prevalence. Considering the fact that $\mathrm{QoL}$ has gained importance and the average life expectancy has been prolonged, the treatment of SUI will become even more important in the following years with the growing geriatric population. The pathophysiology should be objectively confirmed, especially before making a surgical treatment

Table 1. Success Rates of Patients at First and Fifth Years According to IIQ-7 and UDI-6 Scores

\begin{tabular}{|c|c|c|c|c|c|c|c|}
\hline $\begin{array}{l}\text { Postoperative } 1^{\text {st }} \text { Year Success } \\
\text { According to IIQ-7 }\end{array}$ & $\begin{array}{c}\text { Preoperative } \\
\text { IIQ-7 }\end{array}$ & $\begin{array}{l}\text { Postoperative } \\
1^{\text {st }} \text { Year IIQ-7 }\end{array}$ & $\boldsymbol{P}$ & $\begin{array}{c}\text { Postoperative } 1^{\text {st }} \text { Year Success } \\
\text { According to UDI-6 }\end{array}$ & $\begin{array}{c}\text { Preoperative } \\
\text { UDI-6 }\end{array}$ & $\begin{array}{l}\text { Postoperative } 1^{\text {st }} \\
\text { Year UDI-6 }\end{array}$ & $P$ \\
\hline Failure $(n=6)$ & $71.5 \pm 14.1$ & $65.2 \pm 22.4$ & 0.527 & Failure $(n=6)$ & $38.5 \pm 15.9$ & $51.3 \pm 20.8$ & 0.013 \\
\hline Success $(n=73)$ & $69.7 \pm 10.9$ & $1.2 \pm 2.6$ & $<0.001$ & Success $(n=57)$ & $23.9 \pm 8.8$ & $0.1 \pm 0.7$ & $<0.001$ \\
\hline Improvement $(\mathrm{n}=11)$ & $62.6 \pm 5.2$ & $30.9 \pm 14.2$ & $<0.001$ & Improvement $(n=27)$ & $34.8 \pm 8.9$ & $15.9 \pm 6.0$ & $<0.001$ \\
\hline $\begin{array}{l}\text { Postoperative } 5^{\text {th }} \text { Year Success } \\
\text { According to IIQ-7 }\end{array}$ & $\begin{array}{c}\text { Preoperative } \\
\text { IIQ-7 }\end{array}$ & $\begin{array}{l}\text { Postoperative } \\
5^{\text {th }} \text { year IIQ-7 }\end{array}$ & $P$ & $\begin{array}{c}\text { Postoperative } 5^{\text {th }} \text { Year } \\
\text { Success According to UDI-6 }\end{array}$ & $\begin{array}{c}\text { Preoperative } \\
\text { UDI-6 }\end{array}$ & $\begin{array}{l}\text { Postoperative } \\
5^{\text {th }} \text { Year UDI-6 }\end{array}$ & $\boldsymbol{P}$ \\
\hline Failure $(\mathrm{n}=9)$ & $64.4 \pm 15.8$ & $80.7 \pm 17.1$ & $<0.001$ & Failure $(\mathrm{n}=9)$ & $33.0 \pm 8.3$ & $52.6 \pm 12.0$ & $<0.001$ \\
\hline Success $(n=58)$ & $68.8 \pm 9.1$ & $1.6 \pm 3.6$ & $<0.001$ & Success $(n=58)$ & $23.1 \pm 8.2$ & $0.1 \pm 0.8$ & $<0.001$ \\
\hline Improvement $(n=13)$ & $70.4 \pm 12.4$ & $36.6 \pm 15.9$ & $<0.001$ & Improvement $(\mathrm{n}=13)$ & $33.3 \pm 8.8$ & $17.3 \pm 5.6$ & $<0.001$ \\
\hline
\end{tabular}

IIQ-7, Incontinence Impact Questionnaire; UDI-6, Urogenital Distress Inventory-Short Form.

Table 2. Comparison of Preoperative and 1st Year, Preoperative and 5th Year IIQ-7, UDI-6, ICIQ-SF, ICIQ-SF QoL and Q tip Scores

\begin{tabular}{|c|c|c|c|c|c|}
\hline & Preoperative & Postoperative $1^{\text {st }}$ Year & Change in Score & $95 \% \mathrm{Cl}$ & $P$ Value \\
\hline IIQ-7 & $68.9 \pm 9.8$ & $2.8 \pm 15.2$ & $66.2 \pm 16.4$ & $61.9-70.4$ & $<0.001$ \\
\hline UDI-6 & $27.1 \pm 11.1$ & $6.0 \pm 14.6$ & $21.1 \pm 12.1$ & $18.3-23.9$ & $<0.001$ \\
\hline ICIQ-SF & $15.5 \pm 2.5$ & $1.8 \pm 4.3$ & $13.7 \pm 4.0$ & $12.9-14.6$ & $<0.001$ \\
\hline ICIQ-SF QoL & $7.2 \pm 1.4$ & $0.8 \pm 2.0$ & $6.4 \pm 1.9$ & $6.0-6.8$ & $<0.001$ \\
\hline \multirow[t]{2}{*}{ Q tip $\left(^{\circ}\right)$} & $56.2 \pm 17.2$ & $17.1 \pm 12.5$ & $39.2 \pm 16.3$ & $35.8-42.6$ & $<0.001$ \\
\hline & Preoperative & Postoperative $5^{\text {th }}$ Year & Change in Score & $95 \% \mathrm{Cl}$ & $P$ Value \\
\hline IIQ-7 & $66.5 \pm 9.8$ & $9.6 \pm 26.7$ & $56.9 \pm 28.4$ & $49.2-64.6$ & $<0.001$ \\
\hline UDI-6 & $25.0 \pm 8.8$ & $5.1 \pm 10.0$ & $19.9 \pm 10.6$ & $17.4-22.5$ & $<0.001$ \\
\hline ICIQ-SF & $15.5 \pm 2.5$ & $3.1 \pm 5.4$ & $12.4 \pm 4.9$ & $11.3-13.5$ & $<0.001$ \\
\hline ICIQ-SF QoL & $7.2 \pm 1.4$ & $1.4 \pm 2.5$ & $5.9 \pm 2.4$ & $5.4-6.4$ & $<0.001$ \\
\hline Q tip $\left({ }^{\circ}\right)$ & $56.3 \pm 17.3$ & $19.8 \pm 15.9$ & $36.6 \pm 19.4$ & $32.2-40.9$ & $<0.001$ \\
\hline
\end{tabular}

ICIQ-SF, International Consultation on Incontinence short-form questionnaire; IIQ-7, Incontinence Impact Questionnaire; UDI-6, Urogenital Distress InventoryShort Form. 


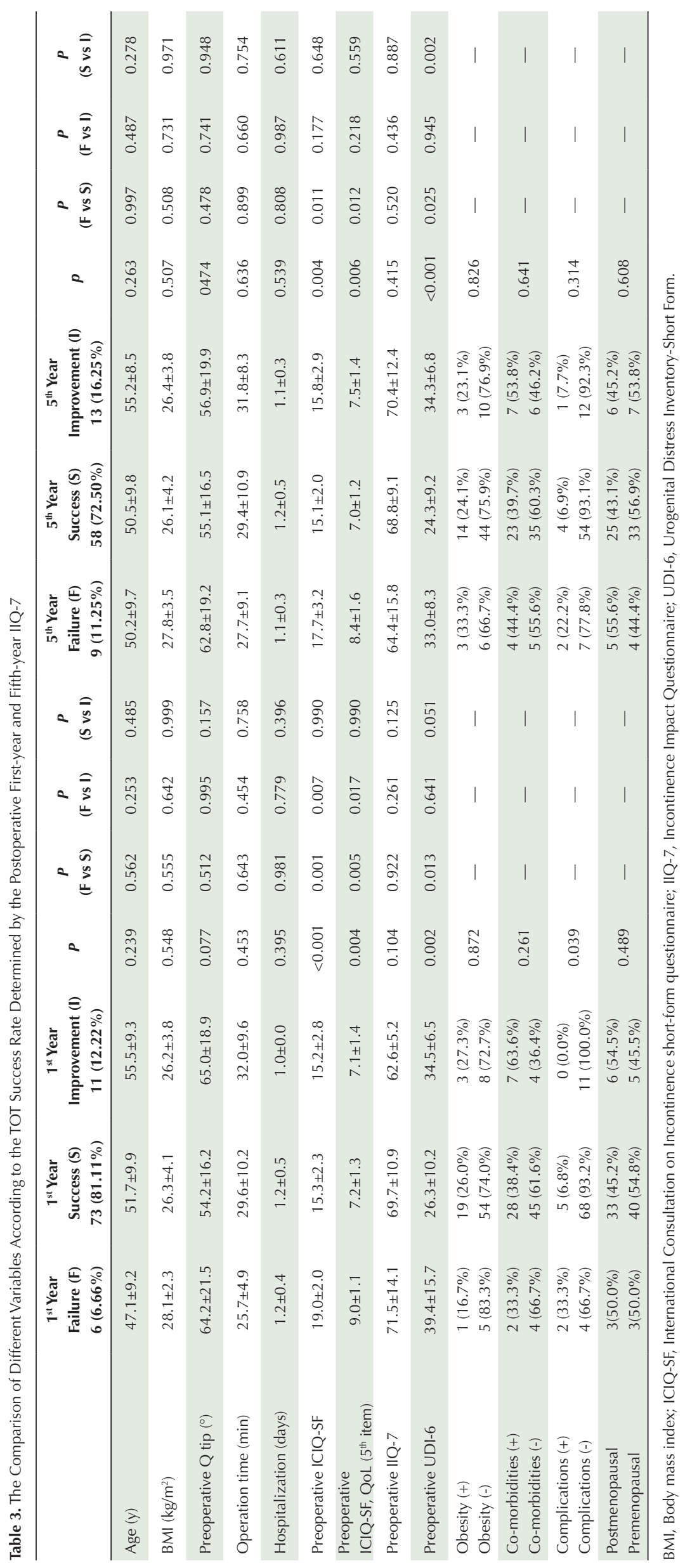




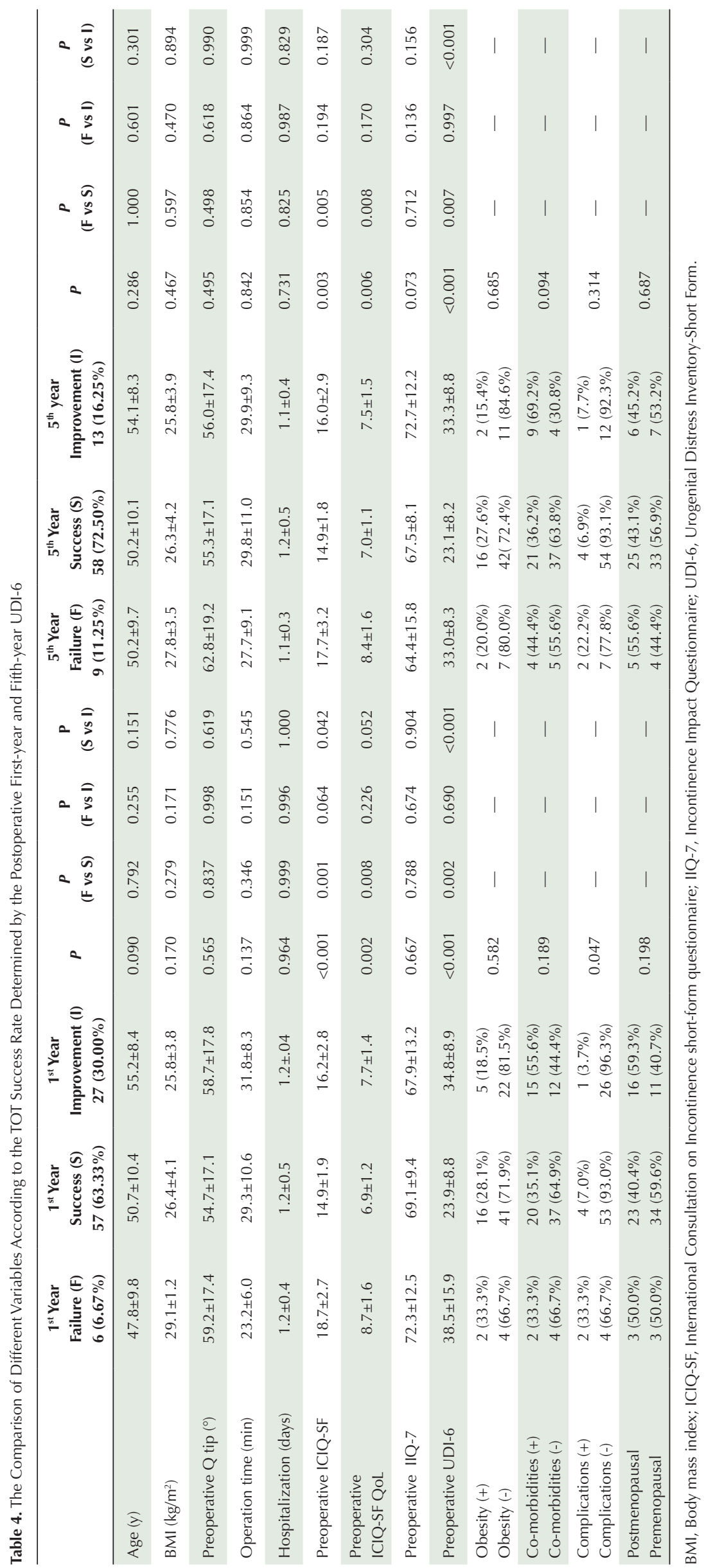


Table 5. Regression Analysis of Success Prediction According to IIQ-7 and UDI-6 in the Postoperative 1st and 5th Years

\begin{tabular}{|c|c|c|c|c|}
\hline & Beta & OR & $95 \% \mathrm{Cl}$ & $P$ \\
\hline \multicolumn{5}{|l|}{ Postoperative $1^{\text {st }}$ IIQ-7 } \\
\hline Preoperative ICIQ-SF & 0.126 & 1.135 & $0.278-4.636$ & 0.861 \\
\hline Preoperative ICIQ-SF QoL & -1.849 & 0.157 & $0.006-4.197$ & 0.270 \\
\hline Preoperative UDI-6 & -0.127 & 0.881 & $0.783-0.991$ & 0.035 \\
\hline \multicolumn{5}{|l|}{ Postoperative $5^{\text {th }}$ year IIQ-7 } \\
\hline Preoperative ICIQ-SF & 0.188 & 1.207 & $0.412-3.536$ & 0.732 \\
\hline Preoperative ICIQ-SF QoL & -1.240 & 0.289 & $0.031-2.704$ & 0.277 \\
\hline Preoperative UDI-6 & -0.104 & 0.902 & $0.809-0.996$ & 0.046 \\
\hline \multicolumn{5}{|l|}{ Postoperative $1^{\text {st }}$ year UDI-6 } \\
\hline Preoperative ICIQ-SF & -0.866 & 0.421 & $0.101-1.746$ & 0.233 \\
\hline Preoperative ICIQ-SF QoL & 0.105 & 1.110 & $0.056-22.203$ & 0.945 \\
\hline Preoperative UDI-6 & -0.128 & 0.880 & $0.762-1.016$ & 0.082 \\
\hline \multicolumn{5}{|l|}{ Postoperative $5^{\text {th }}$ year UDI- 6} \\
\hline Preoperative ICIQ-SF & 0.000 & 1.000 & $0.339-2.947$ & 1.000 \\
\hline Preoperative ICIQ-SF QoL & -1.053 & 0.349 & $0.036-3.350$ & 0.362 \\
\hline Preoperative UDI-6 & -0.126 & 0.881 & $0.793-0.980$ & 0.019 \\
\hline
\end{tabular}

ICIQ-SF, International Consultation on Incontinence short-form questionnaire; IIQ-7, Incontinence Impact Questionnaire; UDI-6, Urogenital Distress Inventory-Short Form.

decision. In the United States of America, the Agency for Health Care Policy Research reported that a preoperative urodynamic examination is not necessary if the symptoms suggest a pure stress type of incontinence, there is no description of an additional micturition problem in the medical history and the physical examination reveals signs of pure stress incontinence. ${ }^{10}$ However, a urodynamic examination is recommended for cases presenting with discrepancies between the medical history, symptoms and micturition diary, those raising a neuropathic bladder suspicion, failure of empirical treatment, clinically unprovable urinary incontinence, history of pelvic surgery and radiotherapy and prominence of obstructive symptoms. ${ }^{10,11}$ In the current study, all patients with complaints of incontinence underwent a preoperative urodynamic examination and those diagnosed with pure stress incontinence were included in the study.

Of the 109 women included in the study, 90 and 80 could be contacted at the end of the first and fifth years, respectively. Thus, our rate of loss to follow-up was $17.4 \%$ for the first year and $26.6 \%$ for the fifth year. Our rates might have increased due to the incomplete or outdated contact information of the patients in the hospital records and the number of older patients who died during the follow-up period. In the study conducted by Canete et al, a similar rate of $32.3 \%$ loss to follow-up was reported at the end of the fifth year. ${ }^{12}$

Canete et al reported that the cough test was negative in $98 \%$ of patients in the first year and $79 \%$ in the fifth year, and $92 \%$ and $72 \%$ of the patients were free of SUI symptoms in the first and fifth years, respectively. ${ }^{12}$ In the current study, the first-year and fifth-year results were $94.4 \%$ and $91.3 \%$, respectively for the negative cough test, and $93.3 \%$ and $88.8 \%$, respectively for the patients who were free of SUI symptoms. We consider that our success rate is higher since our sample only consisted of patients with SUI.

Canete et al calculated the first-year and fifth-year success rates in terms of QoL to be $92 \%$ and $78 \%$, respectively according to UDI-6, and $92 \%$ and $79 \%$, respectively according to IIQ-7. ${ }^{12}$ For the same study, the 10 th year success rates in terms of QoL were reported by Celada et al as $85.7 \%$ according to UDI- 6 and $92.9 \%$ according to IIQ-7. ${ }^{13}$ In the current study, the success rates in terms of QoL were found to be $93.3 \%$ and $88.7 \%$ by UDI-6 and IIQ-7, respectively. In the literature, subjective success rates range from $78 \%$ to $91 \%$ and objective success rates from $75.0 \%$ to $89.3 \% .^{14-16}$ Therefore, despite the high success rates for the first year, there are also researchers presenting these rates as $61.0 \%$ and $65.9 \%$ in the fourth and fifth years, respectively. ${ }^{17,18}$ These conflicting results regarding the long-term outcomes of TOT can be attributed to a variety of factors. Firstly, the definition of the cure rate varies from one study to another. In general, objective measurements are based on the results of the cough stress test, pad test, and urodynamic evaluations. However, subjective evaluation can also be undertaken using patient self-assessment, verified questionnaires, patient satisfaction, and QoL measurement. In the current study, the evaluation of the outcomes following TOT was based on the results of the questionnaires reporting the satisfaction of the patients from a subjective perspective.

In a study by Shkarupa et al, the UDI-6, IIQ-7 and ICIQ-SF scores at 12 months after TOT treatment were found to be significantly decreased compared to the preoperative values. ${ }^{19}$ In a follow-up of 78 patients for an average of 13.5 months after TOT surgery, Huang et al reported a significant decrease in the postoperative UDI-6 and IIQ-7 scores compared to the preoperative values. ${ }^{20}$ In our study, the postoperative IIQ-7, UDI-6 and ICIQ-SF scores were also significantly lower than the preoperative values. This difference continued to be significant at the postoperative fifth year, which is an important finding as it indicates that application of TOT in women with SUI maintains its efficacy in the long term.

According to the results of the IIQ-7 and UDI-6 questionnaires at the end of the first and fifth years, there was an increase in both follow-up visits compared to the preoperative scores in all groups except the first-year IIQ7 score of the TOT failure group. This indicates that even in cases where TOT fails according to the results of IIQ-7 inquiring about the patients' physical, social and mental life, there may be an improvement in the QoL at least in 
the first year, if not in the following years. For the TOT success and improvement groups, the significant decrease in the questionnaire scores compared to the preoperative values continued in the first and fifth years. This shows that the positive contribution of TOT to QoL is maintained in the long term.

Agarwal et al reported that TOT surgery was more successful in premenopausal patients, those younger than 50 years, and those with a urethral mobility of greater than 30 degrees. ${ }^{21}$ In contrast, Yasa et al showed that TOT surgery yielded as successful outcomes for the elderly and postmenopausal patients as for young and premenopausal women. $^{22}$ Esin et al compared obese and non-obese groups and found no effect for obesity on the results of TOT surgery. ${ }^{23}$ In the current study, the first- and fifthyear evaluation of the IIQ-7 and UDI-6 questionnaires revealed that patient age, BMI, preoperative Q-tip angle, obesity, menopause, and preoperative IIQ-7 score did not affect the TOT success rates. However, as the ICIQSF, ICIQ-SF item 5, QoL and UDI-6 scores increased, so did the rates of failure in the first and fifth years. In addition, two patients with perioperative complications were found to have reduced success rate in the first year, but not in the fifth year. Similar to ICIQ-SF and UDI-6 measuring QoL, the questionnaires for the type and degree of incontinence also revealed that the postoperative failure rates increased in parallel to the negative results of the preoperative scores. We consider that the reason why the IIQ-7 preoperative scores were not effective in predicting the long-term outcomes of the operation was that this questionnaire tested the physical, social and mental effects of incontinence.

Arrabal-Polo et al detected a total complication rate of $12 \%$ in their study. ${ }^{24}$ Similarly, Kaelin-Gambirasio calculated the perioperative and early postoperative complication rate as $9.5 \% .{ }^{25}$ The $7.2 \%$ perioperative and early postoperative complication rate in our study supports the notion that the TOT operation is safe. The most severe complication of TOT is bleeding. In this study, only one patient required erythrocyte suspension transfusion, and no hematoma was observed. In the study group, the rate of patients with a blood loss of more than $200 \mathrm{~mL}$ was $2.8 \%$, which is consistent with the findings of Abdel-Fattah et al. $^{26}$

De novo urge incontinence indicates that the obstructive effect of this operation is minimal. Although the etiology of de novo urge incontinence is not clearly known, a review by Abraham and Vasavada, listed the possible causes of this condition as postoperative urinary tract infection (7.4$17.4 \%)$, bladder outflow obstruction (1.9\%-19.7\%), urinary tract perforations $(0.5 \%-5 \%)$, and idiopathic urgency (0-28\%). ${ }^{27}$ In another study, Canete et al reported the rate of de novo urge incontinence at $17 \%$ for the fifth year. ${ }^{12}$ In our study, the rate of de novo urge incontinence was $5.6 \%$ for the first year and $13.8 \%$ for the fifth year.
Our postoperative first-year and fifth-year data reveal that TOT surgery has a high success rate and positive effects on QoL. Low complication rates and ease of application make TOT a good alternative to other treatment modalities in surgical treatment of SUI.

\section{Authors' Contribution}

MOS: Project development, data collection, manuscript writing, final approval of the submited version. VS, BI and GY: Data Collection, manuscript writing, final approval of the submited version.

\section{Conflict of Interest Disclosures}

All authors declare that there is no conflict of interest.

\section{Ethical Statement}

Ethical approval for this study was obtained from the Ethics Committee of Dr. Suat Seren Chest Diseases and Surgery Training and Research Hospital (\#49109414/806.02.02/4977- date: 03.07.2018).

\section{Funding}

This research did not receive any specific grant from any funding agency in the public, commercial or not-for-profit sector.

\section{References}

1. Haylen BT, de Ridder D, Freeman RM, Swift SE, Berghmans B, Lee J, et al. International Urogynecological Association; International Continence Society: An international urogynecological association (IUGA)/international continence society (ICS) joint report on the terminology for female pelvic floor dysfunction. Neurourol Urodyn. 2010;29(1):4-20. doi: 10.1002/nau.20798.

2. Norton PA, MacDonald LD, Sedgwick PM, Stanton SL. Distress and delay associated with urinary incontinence, frequency, and urgency in women. BMJ. 1988;297(6657):1187-9. doi: 10.1136/bmj.297.6657.1187.

3. Abrams P, Cardozo L, Fall M, Griffiths D, Rosier P, Ulmsten U, et al. The standardisation sub-committee of the international continence society. The standardisation of terminology of lower urinary tract function: report from the standardisation subcommittee of the international continence society. Neurourol Urodyn. 2002;21(2):167-78. doi: 10.1002/nau.10052.

4. Staskin D, Kelleher C. Committee 5A initial assessment of urinary incontinence in adult male and female patients. In: Incontinence: 5th International Consultation on Incontinence, edited by Abrams P, Khoury S, Wein AJ, Cardozo L. Paris: ICUD-EAU. 2013;361-88.

5. Garely AD, Noor N. Diagnosis and surgical treatment of stres urinary incontinence. Obstet Gynecol. 2014;124(5):1011-27. doi: 10.1097/AOG.0000000000000514.

6. De Leval J. Novel surgical technique for the treatment for female stress urinary incontinence. Eur Urol. 2001;44(6):72430. doi: 10.1016/j.eururo.2003.09.003.

7. Cerruto MA, Artibani W. Transobturator versus retropubic synthetic slings: Comparative efficacy and safety. Curr Opin Urol. 2011;21(4):275-80. doi: 10.1097/ MOU.0b013e3283476edb.

8. Cetinel B, Ozkan B, Can G. The validation study of ICIQ-SF Turkish version. Turk J Urol. 2004;30(3):332-8.

9. Cam C, Sakalli M, Ay P, Cam M, Karateke A. Validation of the short forms of the incontinence impact questionnaire (IIQ7) and the urogenital distress inventory (UDI-6) in a Turkish population. Neurourol Urodyn. 2007;26(1):129-33. doi: 10.1002/nau.20292.

10. Plazk L, Staskin D. Genuine stres incontinence: Theories of etiology and surgical correction. Urol Clin North Am. 
2002;29(3):527-35. doi: 10.1016/s0094-0143(02)00059-9.

11. Minassian VA, Drutz HP, Al Badr A. Urinary incontinence as a worldwide problem. Int J Gynecol Obstet. 2003;82(3):327-38. doi: 10.1016/s0020-7292(03)00220-0.

12. 12. Cañete $\mathrm{P}$, Ortiz E, Domingo S, Cano A. Transobturator suburethral tape in the treatment of stress urinary incontinence: Efficacy and quality of life after 5 year follow up. Maturitas. 2013;74 (2):166-71. doi: 10.1016/j.maturitas.2012.10.021.

13. Celada P, Cañete P, Ortiz Murillo E, Tarín JJ, Cano A. Effectiveness and quality of life 10 years after transobturator suburethral tape surgery for stress urinary incontinence. J Obstet Gynaecol Res. 2018;44(3):518-23. doi: 10.1111/ jog.13529.

14. Porena M, Costantini E, Frea B, Giannantoni A, Ranzoni S, Mearini $L$, et al. Tension free vaginal tape vs transobturator tape as surgery for stress urinary incontinence: results of a multicentre randomised trial. Eur Urol. 2007;52(5):1481-90. doi: 10.1016/j.eururo.2007.04.059.

15. Grise P, Droupy S, Saussine C, Ballanger P, Monneins F, Hermieu JF, et al. Transobturator tape sling for female stress incontinence with polypropylene tape and outsidein procedure: prospective study with 1 year of minimal follow-up and review of transobturator tape sling. Urology. 2006;68(4):759-63. doi: 10.1016/j.urology.2006.04.020.

16. Houwert RM, Venema PL, Aquarius $A E$, Bruinse HW, Roovers JP, Vervest HA. Risk factors for failure of retropubic and transobturatormidurethral slings. Am J Obstet Gynecol. 2009;201(1):e1-8. doi: 10.1016/j.ajog.2009.04.024.

17. Betari R, Meynier J, Forzini T, François T, Hakami F, Saint F. Is initial success after Monarc(囚) suburethral sling durable at mid-term evaluation?. Prog Urol. 2016;26(7):409-14. doi: 10.1016/j.purol.2016.03.001.

18. Yonguc T, Gunlusoy B, Degirmenci T, Kozacioglu Z, Bozkurt $\mathrm{IH}$, Arslan B, et al. Are the outcomes of transobturator tape procedure for female stress urinary incontinence durable in long-term follow-up?. Int Urol Nephrol. 2014;46(7):1295300. doi: 10.1007/s11255-013-0639-0.

19. Shkarupa D, Kubin N, Staroseltseva O, Shapovalova E. Adjustable transobturator sling for the treatment of primary stress urinary incontinence. Int Urogynecol J. 2018;29(9):13417. doi: 10.1007/s00192-017-3518-x.

20. Huang WC, Lau HH, Su TH. Did surgical failure and complications affect incontinence-related quality of life in women after transobturator sling procedure?. Taiwan J Obstet Gynecol. 2018;57(2):295-9. doi: 10.1016/j.tjog.2018.02.020.

21. Agarwal A, Patnaik P, Shaw D, Rathee V, Khan SW, Jain M, et al. Influence of Demographic and Clinical Factors on Surgical Outcomes of the Transobturator Tape Procedure in Patients with Stress Urinary Incontinence. Curr Urol. 2015;8(3):12632. doi: $10.1159 / 000365703$.

22. Yasa C, Gungorugurlucan F, Dural O, Yumru H, Gunaydin C, Yalcin O. Transobturator tape operation for the treatment of stress urinary incontinence in postmenopausal women aged over 65 years. Low Urin Tract Symptoms. 2018;10(2):153-7. doi: 10.1111/luts.12154.

23. Esin S, Salman MC, Ozyuncu O, Durukan T. Surgical outcome of transobturator tape procedure in obese and nonobese women. J Obstet Gynaecol. 2011;31(7):645-9. doi: 10.3109/01443615.2011.597461.

24. Arrabal-Polo MÁ, Palao-Yago F, Zuluaga-Gómez A, LópezLeón VM, Merino-Salas S, Lahoz-García C, et al. Complications from the placement of a tension-free suburethral sling using the transobturator and retropubic methods for treatment of female urinary incontinence. Urol Int. 2012;89(1):97-102. doi: $10.1159 / 000338643$.

25. Kaelin-Gambirasio I, Jacob S, Boulvain M, Dubuisson JB, Dällenbach P. Complications associated with transobturator sling procedures: Analysis of 233 con-secutive cases with a 27-month follow-up. BMC Womens Health. 2009;9:28-34. doi: 10.1186/1472-6874-9-28.

26. Abdel-Fattah M, Ramsay I, Pringle S, Bjornsson S, Hardwick C, Tierney J, et al. Transobturator suburethral tape in the management of urinary incontinence: success, safety and impact on sexual life. Gynecol Surg. 2007;4:267-73. doi: 10.1007/s10397-007-0308-3.

27. Abraham N, Vasavada S. Urgency after a sling: Review of the management. Curr Urol Rep. 2014;15(4):400-4. doi: 10.1007/ s11934-014-0400-y 